\title{
Strengthening the satisfaction loyalty link: the role of relational switching costs
}

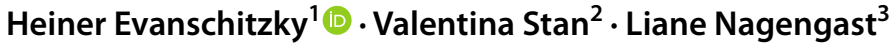

Accepted: 20 July 2021 / Published online: 27 August 2021

(c) The Author(s) 2021

\begin{abstract}
The extant retail research has placed much emphasis on understanding customer switching and the concept of switching costs (SCs). However, the empirical evidence is inconclusive with respect to the moderating role of SCs in general and relational switching costs (RSCs) in particular. Therefore, this research focuses on the moderating role played by SCs on the satisfaction-loyalty link. Specifically, our study attempts to clarify the nonlinear moderating effect of RSCs. Furthermore, we investigate RSCs in greater depth, considering their two dimensions, brand relationship loss costs (BRLCs), and personal relationship loss costs (PRLCs). We find that there is an optimal level of BRLC whereas increasing PRLCs decreases the impact of satisfaction on loyalty in a linear manner, calling for a more nuanced assessment of this type of SC in future studies. Our findings contribute to a deeper understanding of the effectiveness of SCs as a retention strategy.
\end{abstract}

Keywords Switching costs · Customer satisfaction · Loyalty $\cdot$ Relational switching costs

Heiner Evanschitzky

heiner.evanschitzky@manchester.ac.uk

Valentina Stan

valentina.stan@essca.fr

Liane Nagengast

liane.nagengast@unisg.ch

1 Alliance Manchester Business School, Booth Street West, Manchester M15 6PB, UK

2 ESSCA School of Management, 55 Quai Alphonse Le Gallo, 92513 Boulogne-Billancourt Cedex, France

3 Institute of Retail Management, University of St, Gallen, St. Gallen, Switzerland 


\section{Introduction}

As the acceptance of information and communication technologies creates disruption in purchase behavior, the building and sustaining of customer loyalty remains an ongoing challenge for retailers (e.g., Evanschitzky et al., 2020). Loyalty has been shown to affect important downstream outcomes (e.g., Evanschitzky et al., 2012; Love et al., 2016; Mende et al., 2015), and it has been suggested that finding new customers is costlier than retaining existing customers (e.g., DavisSramek et al., 2009). Therefore, research has placed much emphasis on assessing customer switching in general (e.g., Jones et al., 2000, 2002, 2007; Popkowski Leszczyc \& Timmermans, 1997) and the impact of switching costs (SCs) on loyalty in particular (e.g., Blut et al., 2014, 2016; Nagengast et al., 2014; Pick \& Eisend, 2014).

Switching costs are the (monetary and nonmonetary) costs a customer faces when switching to a new provider (Nagengast et al., 2014; Pick \& Eisend, 2014). Considering different industries, one meta-analysis (Pick \& Eisend, 2014) demonstrated that SCs reduce switching and play a key role in explaining customer repurchase behaviors. Nagengast et al. (2014) further developed these findings by examining not only the direct effect of SCs on repurchase behavior but also their moderating effect. In a more nuanced assessment, the above authors found evidence of an inverted U-shaped moderating effect of overall SCs (OSCs) on the relationship between satisfaction and loyalty. The above study was conducted in three industries and suggested the existence of an optimal level of SCs. Furthermore, Nagengast et al. (2014) distinguished between different types of SCs and showed that the moderating effects are different for financial, procedural, and relational SCs. Specifically, the inverted U-shaped moderating effect is significant and most prevalent for financial SCs. Conversely, procedural SCs exert a linear (i.e., negative) moderating effect on the relationship between satisfaction and loyalty, which is in line with combined meta-analytical evidence (Blut et al., 2015).

Regarding the moderating effect of relational switching costs (RSCs), the existing results are less clear. Nagengast et al. (2014) found a marginally significant inverted U-shaped moderating effect on the satisfaction-loyalty link. In contrast, meta-analytic evidence has shown that higher RSCs weaken the association between satisfaction and loyalty (Blut et al., 2015), suggesting a negative linear moderating effect. Thus, a considerable lack of clarity still exists as to how to best specify the nature of this functional form.

The lack of empirical clarity on the role of RSCs is noteworthy, in particular because of the growing importance of RSCs in marketing practice (e.g., Sashi, 2012). Many examples, such as personalized product offers, individual consultation through digital platforms, and communication through social networks, are already widely used. Given the evolution of innovative technologies such as, for instance, the Internet of Things and augmented reality applications, relationship marketing will become even more essential in the near future.

As RSCs gain importance, it is necessary for marketing theory and practice to understand their role in the formation of customer loyalty. Therefore, we will 
investigate the moderating effect of RSCs in greater depth by considering their two dimensions: brand relationship loss costs (BRLCs) and personal relationship loss costs (PRLCs). While BRLCs are perceived as affective losses caused by breaking up the customer-brand relationship, PRLCs are perceived as losses caused by breaking up the personal relationship (friendship) with people (i.e., employees) of a specific company (Burnham et al., 2003; Jones et al., 2007).

By providing insights into how to manage RSCs, this in-depth study has major implications for retention strategies. Companies that previously had not been interested in RSCs are now re-examining their strategies. For example, Free, a major French telecommunications service provider, is making considerable efforts toward building RSCs. Initially, the company competed mainly in terms of price and did not engage with customers beyond simple transactions such as renewing a contract. Free decided to open physical stores, train sales staff, and improve customer services, thereby increasing its RSCs. An important question, however, is how to manage RSCs in a retention strategy. Specifically, how can Free consider the role of BRLCs and PRLCs to strengthen the satisfaction-loyalty relationship?

In addition, we re-examine the nonlinear moderating effect of OSCs. A large number of empirical studies have considered that OSCs moderate the relationship between satisfaction and loyalty in a positive or negative manner. Bringing together conflicting theories, Nagengast et al. (2014) found an inverted U-shaped moderating effect, and while their theoretical argument is crucial for academics and practitioners, related empirical evidence remains scarce.

In sum, our study offers the following contributions for marketing theory and practice. First, and in line with Nagengast et al. (2014), we show that the moderating effect of OSCs is nonlinear. This insight is important since the studies reported by Nagengast et al. (2014) were conducted in a European context, and thus, the findings may not be readily transferable to other important national contexts such as the USA. Thus, our study enhances the generalizability of this seminal work. Satisfaction is an even more important predictor of loyalty in situations characterized by an optimal level of OSCs. This substantiation is important since knowledge about nonlinear effects contributes to the effectiveness of SCs as a retention strategy.

Second, we clarify the inconsistent previous results concerning the moderating effect of RSCs. Specifically, this research provides a deeper understanding of RSCs, considering their two dimensions. We theoretically derive that BRLCs are classified as positive SCs, while PRLCs are classified as negative SCs. The findings presented here suggest that there is an optimal level of BRLC whereas increasing PRLCs decreases the impact of satisfaction on loyalty in a linear manner. The distinction between the two dimensions allows for the efficient allocation of resources when seeking to enhance loyalty. It is worth noting that our study represents the first attempt to examine the nonlinear moderating effect of BRLCs and PRLCs.

This paper starts by considering the moderating role of OSCs, followed by an assessment of RSCs (studies 1 and 2) and an investigation of the moderating role of the two dimensions of RSCs (study 3). We continue by outlining the theoretical and managerial implications of our findings. The last sections summarize the paper and provide an agenda for further research. 


\section{The moderating effect of switching costs}

In their assessment of the role of SCs on the satisfaction-loyalty link, Nagengast et al. (2014) synthesized two opposing moderating effects. The first is an "amplifying effect" (positive moderating effect), suggesting that increasing SCs reinforce the effect of satisfaction on loyalty, mainly because of increased "staying costs" such as boredom or lack of variety (Chang \& Chen, 2009; Lee et al., 2001; Yang \& Peterson, 2004). The second effect is the "lock-in effect" (negative moderating effect), whereby decreasing satisfaction levels will not automatically result in decreased loyalty if SCs are high because customers will face additional costs if they change their provider (Bell et al., 2005; Dick \& Basu, 1994).

Nagengast et al. (2014) argued that if SCs are low, then the amplifying effect is stronger than the lock-in effect, and thus, increasing SCs strengthens the satisfaction-loyalty link. In contrast, when SCs are high, the amplifying effect becomes less important, and the lock-in effect is prevalent; thus, further increases in SCs weaken the satisfaction-loyalty link. Hence, the combined effect has an inverted U-shape, which implies that the relationship between satisfaction and repurchase behavior will be strongest when SCs reach an optimal level. Nagengast et al. (2014) found robust empirical evidence for such an inverted U-shaped moderating effect of OSCs.

Concerning RSCs, the expectation is that under low levels of RSCs, satisfied customers will still behave in a disloyal manner to a certain extent. Therefore, high satisfaction will not fully compensate for low RSCs. On the other hand, high RSCs will be unnecessary and lead to an inefficient allocation of marketing resources if satisfaction levels are high. However, if RSCs exert a linear negative moderating effect (as suggested by some studies), satisfaction and switching costs will compensate for each other to such an extent that high RSCs will buffer low levels of satisfaction, and vice versa. If RSCs are low, then high satisfaction levels will still lead to loyal customers, so higher investments in RSCs will not be absolutely essential. Hence, depending on the level of customer satisfaction, lower or higher RSCs can be most efficient. If customers are satisfied, then it may not be advantageous to make further investments in RSCs from a cost-benefit perspective. In contrast, if satisfaction is low, then high RSCs will still ensure strong customer loyalty.

Similarly, Nagengast et al. (2014) justified their nonlinear moderating effect by analyzing negative vs. positive SCs. This classification (negative vs. positive SCs) is based on "the underlying nature of constraint involved" (Jones et al., 2007, p. 337). Specifically, SCs are considered positive when any benefit or reward from a current relationship is given up. Negative SCs refer to an actual loss in terms of time and effort, which arises if a customer switches (e.g., Nagengast et al., 2014).

In line with Nagengast et al. (2014), we consider that "positive SCs are foregone benefits from the current relationship when switching to a new provider, whereas negative SCs represent actual losses associated with the switching process" (p. 409).

The above authors argued that these types of SCs exert different moderating effects on the satisfaction-loyalty link. Procedural SCs are negative SCs, as they 
denote actual losses and arise from negative sources of constraint (Jones et al., 2007). According to prospect theory, customers perceive even small losses as being substantial and painful. Hence, even low, negative SCs will prevent customers from switching; they do not moderate the relationship between satisfaction and loyalty in an inverted U-shaped manner but in a negative way.

In contrast, relational and financial SCs emerge from positive sources of constraints and denote forgone gains ${ }^{1}$ (Jones et al., 2007). While even small losses prevent customers from switching, small forgone gains may not do so. Nagengast et al. (2014) therefore expected an inverted U-shaped moderating effect of positive SCs. However, the findings of their study showed only some directional evidence for this moderating effect of RSCs, thus warranting closer investigation. Clarifying the role of the moderating effect of RSCs will then allow us to investigate them in greater depth by considering their two dimensions.

\subsection{Study 1: Testing the inverted U-shaped moderating effect of OSCs ${ }^{2}$}

\subsubsection{Sample and methodology}

The data for study 1 comes from a survey administered to members of a representative panel of the US population. In order to be considered for participation, an individual must regularly shop at the focal retailer ("Retailer 1"). Using quota sampling (Deville, 1991) a total of $n=6674$ individuals were recruited. After removing incomplete surveys, a total of 6458 valid questionnaires remained (sample statistics are provided in Appendix 1).

The scales employed were adapted from prior research (see Appendix 2). In particular, we borrowed a two-item loyalty measure from Vogel et al. (2008) and a two-item overall satisfaction measure proposed by Fornell et al. (1996). The measurement model was tested by assessing construct reliability and convergent and discriminant validity. Appendix 3 shows that all constructs meet the generally accepted criteria (Fornell \& Larcker, 1981). In line with Nagengast et al. (2014), the variables were mean-centered to improve the interpretability of the findings (Aiken \& West, 1991); and then, each latent variable was summarized by its mean score.

The distributions of the satisfaction and loyalty data were negatively skewed. This phenomenon is common with satisfaction surveys in competitive markets since existing customers often rate their focal provider favorably (Nagengast et al., 2014; Vogel et al., 2008). The findings reported in Appendix 1 indicate that the skewness (SK) values for satisfaction and loyalty are approximately -1, which is in line with the acceptable levels (Darren \& Mallery, 2019; Muthen \& Kaplan, 1985).

\footnotetext{
1 Forgone gains refer to the potential loss of special discounts and unique benefits if a consumer switches from her or his current service provider to another.

${ }^{2}$ While OSCs can be seen as a crude measure of SCs compared to the more fine-grained operationalization, we introduce later; given their brevity, OSCs have the advantage of being easy to administer as a proxy for SCs so that companies can include them in their annual customer surveys.
} 
Table 1 Results of regression analysis (study 1)

\begin{tabular}{|c|c|c|c|c|}
\hline & \multicolumn{2}{|c|}{ Model 1} & \multicolumn{2}{|c|}{ Model 2} \\
\hline & $b$ & $t$ & $b$ & $t$ \\
\hline \multicolumn{5}{|l|}{ Predictor variable } \\
\hline Constant & .023 & $2.249 * *$ & .056 & $2.896 * * *$ \\
\hline SAT & .321 & $57.320 * * *$ & .299 & $51.159 * * *$ \\
\hline OSC & .022 & $5.267 * * *$ & .011 & $2.521 * * *$ \\
\hline $\mathrm{OSC}^{2}$ & -.006 & $-4.006^{* * *}$ & -.008 & $-4.763^{* * *}$ \\
\hline SAT x OSC & .004 & $1.905^{*}$ & .003 & $1.679 *$ \\
\hline SAT $x$ OSC $^{2}$ & -.002 & $-2.262 * *$ & -.001 & $-2.069 * *$ \\
\hline \multicolumn{5}{|l|}{ Co-variables } \\
\hline Gender-1 & & & -.088 & $-5.472 * * *$ \\
\hline Gender-2 & & & .000 & \\
\hline Age-35-54 & & & .041 & $2.003 * *$ \\
\hline Age-55 and more & & & -.020 & -.939 (n.s.) \\
\hline Age-under 35 & & & .000 & \\
\hline Location & & & .041 & $11.477 * * *$ \\
\hline$R^{2}$ & .483 & & .496 & \\
\hline
\end{tabular}

Gender-1: Male

Note: Model errors, $\mathrm{SK}=-.787$

${ }^{*} p<.10$

${ }^{* *} p<.05$

**** $p<.01$

\subsubsection{Empirical findings}

An ordinary least squares (OLS) regression analysis was performed with customer loyalty as the dependent variable. In the first step, the model was estimated using the main effects and the linear and quadratic interaction terms of OSCs (model 1).

The results for the US retailer are presented in Table 1. Our findings reveal that the predictor variables explain substantial amounts of variance in the endogenous variable $\left(R^{2}=0.483 ; p<0.001\right)$. Model 1 shows that satisfaction $(b=0.321$; $p<0.001)$ and OSCs $(b=0.022 ; p<0.001)$ have positive effects on customer loyalty. Moreover, the linear moderating effect of OSCs is marginally significant $(b=0.004$; $p<0.10$ ). Importantly, as in the study by Nagengast et al. (2014), we find an inverted U-shaped moderating effect of OSCs on the relationship between satisfaction and loyalty $^{3}(b=-0.002 ; p<0.05)$.

The results strongly confirm an inverted U-shaped moderating effect of OSCs in the context of a US department store retailer. Furthermore, we observe that the maximum influence of the OSCs' quadratic effect is obtained when OSCs $=0.96$ (Fig. 1),

\footnotetext{
3 Note that our study does not use the exact same measure of loyalty as Nagengast et al. (2014). It thereby offers an additional robustness check for the original study.
} 

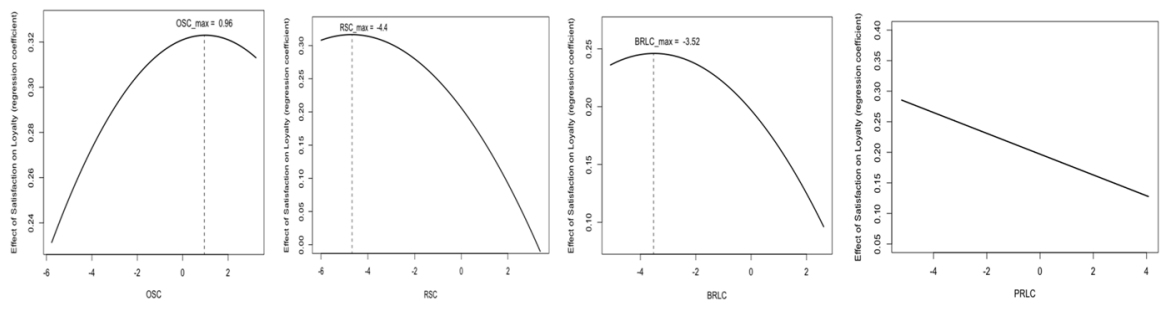

Fig. 1 Plot between SCs and effect of satisfaction on loyalty

that is, for a value close to the mean score. Values higher or smaller than this point weaken the relationship between satisfaction and loyalty. To rule out potential missing variable bias, we control for gender, age, and the perceived convenience of store location in the second step (model 2). Our analyses confirm the previous findings (see Table 1).

\subsection{Study 2: Testing the inverted U-shaped moderating effect of RSCs}

\subsubsection{Sample and methodology}

We examine the moderating effect of RSCs on the relationship between satisfaction and loyalty with data from the same retailer (retailer 1; $n=6458$ ). Furthermore, we had access to customer data from two other large US department store retailers, retailer 2 ( $n=4254 ; n=4104$ after deleting incomplete surveys; retailer 3, $n=4741$; $n=4558$ after deleting incomplete surveys) (see Appendix 1 for sample statistics ${ }^{4}$ ). Data collection was identical to the process used for retailer 1. A consumer who mainly shopped at retailer 1 was not necessarily familiar with retailers 2 or 3 .

The measurement model was the same as in study 1 for satisfaction and loyalty; the items for capturing RSCs were in line with those used in prior research (see Appendix 2). The reliability and validity of the constructs were acceptable (Appendices 2 and 3). As in study 1, variables were mean-centered, and then, summarized by its mean score.

\subsubsection{Empirical findings}

As was done in study 1, an OLS regression analysis was performed. First, we estimated the model including the main effects and the linear and quadratic interaction terms of RSCs (model 1). Table 2 presents the regression results for all three US retailers. The nonlinear model explains substantial amounts of variance in loyalty for all retailers (retailer $1, R^{2}=0.538 ; p<0.001$; retailer $2, R^{2}=0.504 ; p<0.001$; retailer $\left.3, R^{2}=0.505 ; p<0.001\right)$. As in Nagengast et al. (2014), we found positive main effects of satisfaction and RSCs on loyalty.

\footnotetext{
4 The skewness (SK) values for satisfaction and loyalty are around -1 , which is an acceptable level.
} 


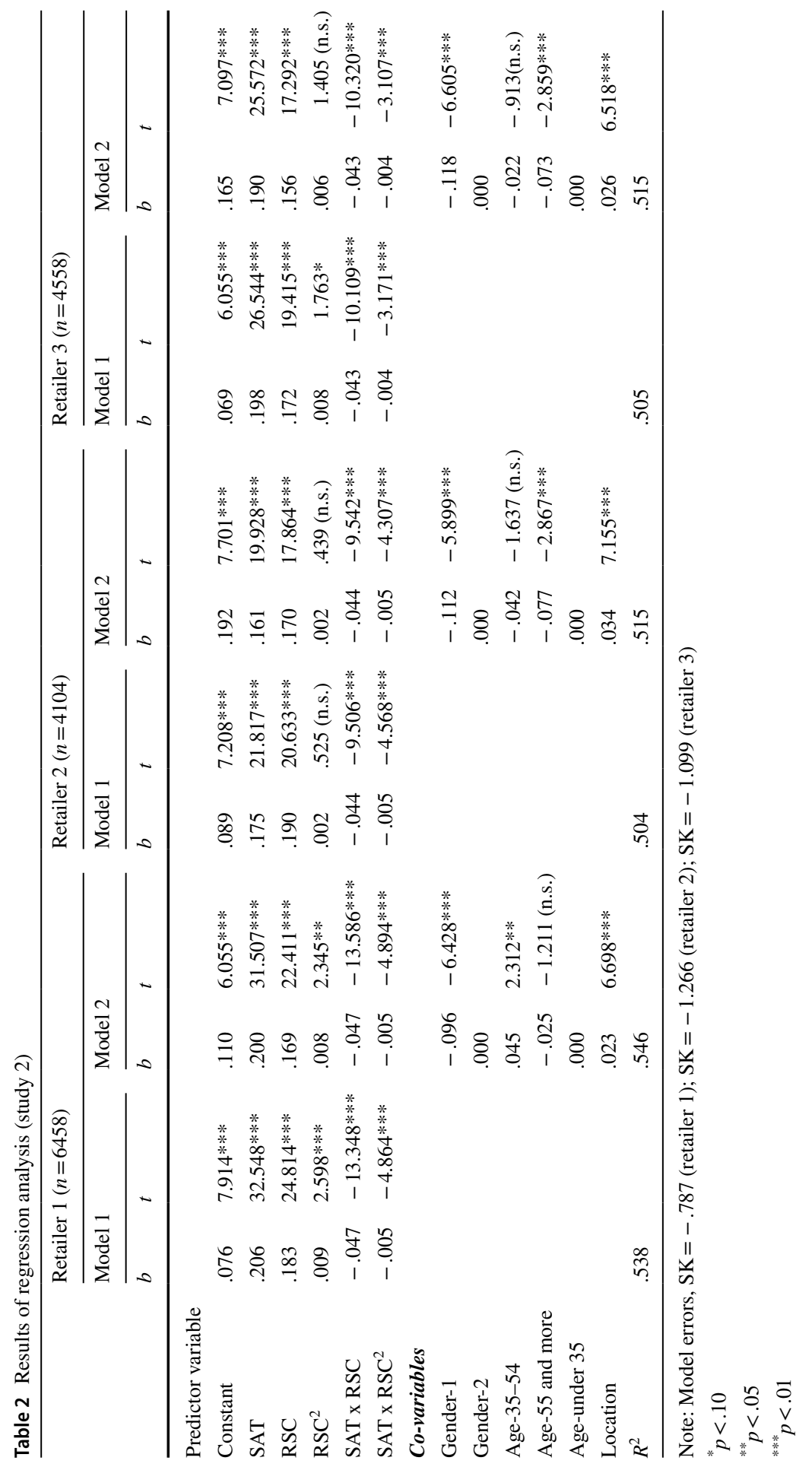


Furthermore, we observe a significant nonlinear moderating effect of RSCs (retailer 1, $b=-0.005 ; p<0.001$; retailer 2, $b=-0.005 ; p<0.001$; retailer 3 , $b=-0.004 ; p<0.01)$. We conclude that RSCs moderate the relationship between satisfaction and loyalty in an inverted U-shaped manner for all three US department stores.

To gain further insights into this finding, we plot the influence of RSCs on the relationships between satisfaction and loyalty for retailer $1 .^{5}$

We observe that the maximum influence of RSCs' quadratic effect is obtained for RSC scores close to -4.4 , that is, for values smaller than the mean scores. Second, we include gender, age, and the perceived convenience of store location as covariates. Model 2 shows that the previous findings are confirmed (Table 2).

\section{Two-dimensional conceptualization of RSCs}

Although RSCs are typically considered positive SCs (e.g., Blut et al., 2015, 2016; Nagengast et al., 2014), we propose a more nuanced view, i.e., differentiating between their two dimensions: brand relationship loss costs (BRLCs) and personal relationship loss costs (PRLCs) (Burnham et al., 2003). In doing so, our study can help increase the understanding of the mechanism through which RSCs moderate the relationship between satisfaction and loyalty.

As suggested by prior research (Blut et al., 2015), both dimensions of RSCs are important, as both brand and personal relationships hinder customer switching. BRLCs and PRLCs are created by the provider to generate additional benefits for the consumers for the purpose of binding them to the firm (Blut et al., 2015). Both types of switching costs are perceived by customers as losses due to giving up a relationship with a provider. However, closer scrutiny of the two dimensions shows that they differ conceptually since the nature of their relationship is not the same. Specifically, PRLCs refer to friendship. As argued by Price and Arnould (1999), "Friendship is portrayed as a voluntary, personal relationship, typically providing intimacy and assistance, in which the two parties like each other and seek each other's company" (p. 39). Thus, by friendship, customers mean that they feel a sense of intimacy with the employees and that these employees care about them. As a result, customers feel comfortable sharing their true feelings (Price \& Arnould, 1999).

Building friendship requires time and effort (Rusbult, 1980) not only for employees but also for customers. This is even more difficult in service settings because providers and clients often come from different social environments, so they need to overcome their differences (Price \& Arnould, 1999). Giving up a friendship leads to stress and negative feelings (e.g., sadness and guilt), which in turn can lead to increased cognitive and emotional efforts. Moreover, the time spent building a friendship is perceived as a significant resource. When abandoning this relationship, individuals sacrifice their invested resources and, thus, are faced with real losses.

\footnotetext{
5 The graphs for retailers 2 and 3 are similar.
} 
An important point to consider, however, is that switching is often caused by service failures. The negative events that occur are understood as a sign of a deeper incompatibility, thus challenging the foundation of the relationship (Harmeling et al., 2015) and leading individuals to focus even more on the sacrifices they made. Accordingly, PRLCs are derived mainly from negative sources of constraint, acting as negative switching costs.

BRLCs, conversely, describe regret or loss of comfort due to not experiencing specific benefits (e.g., prestige, status, and reputation). Customers may choose a particular brand, for instance, to express their social status, to communicate and share with others through self-presentation (e.g., Swaminathan et al., 2007). If a consumer were to change the current provider, then it might be perceived mainly as a lost benefit to no longer support or interact with a specific company (Burnham et al., 2003). For example, an Apple customer who is switching to Android may still perceive the reputation of Apple as prestigious and, hence, consider switching to be a loss of (reputational) brand benefits. Therefore, these costs arise mainly from positive sources of constraints. In this respect, BRLCs are classified as positive SCs, representing forgone benefits.

In sum, a loss is perceived differently depending on whether it is a loss of benefits (BRLCs) or a loss primarily due to sacrifices made (time and effort) by customers (PRLCs).

Consistent with Nagengast et al. (2014), we argue that even low, negative SCs prevent satisfied customers from switching, and thus, the amplifying effect will be undermined and the lock-in effect will dominate (even for low PRLCs). Therefore, we do not expect PRLCs to have an inverted U-shaped moderating effect on the relationship between satisfaction and loyalty. Instead, we expect a negative moderating effect. In contrast, we suppose that BRLCs have an inverted U-shaped moderating effect on the relationship between satisfaction and loyalty, as they constitute positive SCs.

\subsection{Study 3: Testing the moderating effect of BRLCs and PRLCs}

\subsubsection{Sample and methodology}

We test the above hypothesized relationships using the same retailers from our previous analysis (retailer 1, $n=6458$; retailer 2, $n=4104$; retailer 3, $n=4558$ ). Furthermore, we measure BRLCs and PRLCs with established scales (see Appendix 2); all other scales are identical to those used previously (see Appendices 2 and 3 for details). To rule out potential missing variable bias, we control for gender, age, and the perceived convenience of store location. We apply hierarchical linear modeling (HLM) to the pooled data, allowing for a random error at level 2 to account for the nested data structure.

\subsubsection{Empirical findings}

The results of the multilevel model (log-likelihood $=-11,680.994$; $\mathrm{AIC}=23,385.988 ; \mathrm{BIC}=23,475.723$ ) are reported in Table 3. We find that satisfaction, BRLCs, and PRLCs have positive effects on loyalty $(b=0.432 ; p<0.01$; $b=0.281 ; p<0.01 ; b=0.093 ; p<0.01)$. Our findings further support the view that 
Table 3 Results of hierarchical linear modeling (study 3)

\begin{tabular}{|c|c|c|c|c|c|c|}
\hline & \multicolumn{3}{|l|}{ Model 1} & \multicolumn{3}{|c|}{ Model 2} \\
\hline & $B$ & $b$ & $t$ & $B$ & $b$ & $t$ \\
\hline Satisfaction (SAT) & .197 & .432 & $35.030 * * *$ & .190 & .418 & $31.166^{* * *}$ \\
\hline $\begin{array}{l}\text { Brand relationship lost } \\
\text { costs (BRLC) }\end{array}$ & .170 & .281 & $17.292 * * *$ & .159 & .263 & $14.849 * * *$ \\
\hline $\begin{array}{l}\text { Personal relationship lost } \\
\text { costs (PRLC) }\end{array}$ & .040 & .093 & $6.987 * * *$ & .035 & .081 & $5.967 * * *$ \\
\hline PRLC $^{2}$ & .005 & .031 & $1.907 *$ & .004 & .024 & 1.499 (n.s.) \\
\hline BRLC $^{2}$ & .001 & .004 & .276 (n.s.) & .001 & .002 & .171 (n.s.) \\
\hline SAT x BRLC & -.028 & -.109 & $-6.544 * * *$ & -.029 & -.111 & $-6.964 * * *$ \\
\hline SAT $x$ BRLC $^{2}$ & -.004 & -.059 & $-3.978 * *$ & -.004 & -.060 & $-4.077 * * *$ \\
\hline SAT x PRLC & -.017 & -.088 & $-5.554 * * *$ & -.017 & -.086 & $-4.919 * * *$ \\
\hline SAT x PRLC ${ }^{2}$ & -.001 & -.015 & -.892 (n.s.) & -.001 & -.012 & -.702 (n.s.) \\
\hline $\begin{array}{l}\text { Co-variables } \\
\text { Gender }\end{array}$ & & & & .100 & .058 & $5.631 * * *$ \\
\hline Age & & & & -.017 & -.014 & -1.172 (n.s.) \\
\hline Location & & & & .023 & .065 & $6.864 * * *$ \\
\hline Loglikelihood & $-11,680.994$ & & & & $-11,601.815$ & \\
\hline AIC & $23,385.988$ & & & & $23,233.629$ & \\
\hline BIC & $23,475.723$ & & & & $23,345.798$ & \\
\hline
\end{tabular}

BRLCs moderate the relationship between satisfaction and loyalty in an inverted U-shaped manner $(b=-0.059 ; p<0.01)$, whereas increasing PRLCs decreases the impact of satisfaction on loyalty in a linear manner $(b=-0.088 ; p<0.01)$.

Figure 1 shows that the maximum influence of the BRLCs' quadratic effect is obtained when BRLCs $=-3.5$. For values higher or smaller than this optimum point, the relationship between satisfaction and loyalty decreases.

\section{Discussion}

This study intends to shed light on the moderating effect of SCs on the satisfactionloyalty relationship and thereby develops genuine knowledge concerning the role of SCs in the customer retention process. The results of our analyses show strong evidence in line with Nagengast et al. (2014) with respect to the moderating effect of OSCs such that an optimal level strengthens the relationship between satisfaction and loyalty. The robustness of these outcomes is enhanced since our measure of loyalty is slightly different from that used by Nagengast et al. (2014).

This statement is theoretically important and reveals that Nagengast et al.'s (2014) findings are not idiosyncratic to their chosen context. Retailers often use switching costs as a strategy for retaining customers. However, they must be mindful that increasing SCs beyond an optimal level will actually weaken the satisfactionloyalty link. 
We further find that RSCs moderate the relationship between satisfaction and loyalty in a nonlinear way. Different from Nagengast et al.'s (2014) findings, we confirm the theoretical assumption of an inverted U-shape for all three US department stores. Thus, increasing RSCs strengthens the relationship between satisfaction and loyalty up to an optimal point. Beyond this point, increasing RSCs weaken this relationship. A balance has to be found between locking-in customers by means of RSCs and granting customers some freedom to choose between providers.

Based on theoretical grounds, we use a two-dimensional conceptualization of RSCs, which allows researchers and managers to examine this type of SC more finely. When customers must break a bond with a provider brand (BRLCs) or with an employee (PRLCs), it may result in emotional discomfort (Blut et al., 2014). Our study is the first to distinguish between these two dimensions and provides evidence as to how they produce different outcomes relative to their moderating effects. Table 3 shows that BRLCs and PRLCs directly affect loyalty. Furthermore, the results support the view that BRLCs moderate the relationship between satisfaction and loyalty in an inverted U-shaped manner, whereas increasing PRLCs decreases the impact of satisfaction on loyalty in a linear manner. Accordingly, it is more appropriate to distinguish between the two dimensions and consider their varying effects when developing strategies for satisfaction and SC management.

When BRLCs reach an optimal level, customer retention activities will be most effective, and satisfaction will directly translate into loyalty. Hence, retailers should aim at reaching an optimal level of BRLCs to build long-term relationships with their customers. This could, for instance, be achieved through branding activities on various channels, such as TV, social media, print advertising, and mobile devices. However, below-the-line activities, such as sponsorship or charitable engagements, might be even more effective in fostering brand relationships. These activities should be used in moderation, however, since the conventional view is that high BRLC payoff levels are not adequate with respect to the satisfaction-loyalty link. While BRLCs beyond an optimal level may not necessarily harm a brand's relationship with a customer, the marketing budget could be spent in a more efficient way.

For PRLCs, we find a linear negative moderating effect, suggesting that when PRLCs increase, the relationship between satisfaction and loyalty diminishes. The higher the PRLCs are, the less important becomes satisfaction as a driver of loyalty. Strengthening PRLCs will support customer loyalty and make customer satisfaction less crucial. Retailers have various possibilities for building PRLCs. First, frontline employees play an important role. Having a personal relationship with salespeople will increase PRLCs and, thus, customer loyalty. Our results suggest that even if customers are not fully satisfied with a retailer, their friendships with sales employees may prevent them from switching. It is worth noting that employees will be more likely to interact with customers and create friendships (Price \& Arnould, 1999) if they are happy at work. Second, personalized product offers provide the possibility to communicate with customers on a personal level and strengthen PRLCs. Sending personalized product suggestions or discounts (e.g., based on stated preferences or past purchase behaviors) can enhance relationships with customers and support increases in PRLCs. Third, social media offers vast possibilities for communicating with customers on a personal level. For example, retailers can provide personal 
content through social media, such as introducing new employees, providing information about their CEO, or asking their customers for feedback on new products.

Returning to our example, as direct and regular interactions between employees and customers are likely to develop into relationships between the two parties, Free, the telecommunications service provider, decided to open physical stores and invest in staff training. When employees are well trained, well supported, and empowered, they are able to develop genuine human contact. Doing that requires additional investments in employees, but these investments might pay off as they will have consequences on the satisfaction-loyalty link: Even short-term decreases in the customer satisfaction level (i.e., through service failure) can be buffered by PRLCs. Furthermore, the company has increased its investments in BRLCs (e.g., expanding its brand community on Facebook and aiming at sustainable development). In their resource allocation decisions, managers should consider that an optimal level of BRLCs will provide a better payoff. Aside from focusing on SCs, it is important to note that high levels of customer satisfaction should still remain a key objective. Otherwise, dissatisfied customers will switch as soon as SCs decrease.

\section{Limitations and future research}

As with all empirical research, this study is subject to certain limitations. First, the research context was limited to US retail department stores. Therefore, it is unclear whether the patterns detected here can be generalizable to other sectors or countries. Future research is needed to address this gap.

Second, the present study used cross-sectional data. It would be of great interest for researchers and managers to use longitudinal research designs since customer perceptions of SCs may evolve over time. This would also address the potential bias of demand artifacts caused by unobservable fixed effects at the individual customer level.

Third, future research should revisit the original scales used by Nagengast et al. (2014) to measure BRLCs and PRLCs. In particular, the aspect of "potential losses" could be captured better. To measure customer satisfaction, we used a "short" scale, which is not a concern in our case given the sample size. We acknowledge that more comprehensive measures for this concept should be employed in future research. To provide a deeper understanding regarding the moderating effects of BRLCs and PRLCs, it would also be interesting to consider the different dimensions of customer loyalty.

Forth, given the limitation of our data, future research should investigate how various aspects of the customer experience are related directly and indirectly (via satisfaction) to loyalty. Examining the moderating role of customer experience on the satisfaction-loyalty link would also offer a more complete assessment of this relationship.

Furthermore, we suggest including more control variables to account for potential customer heterogeneity. Another useful extension would be to examine other possible nonlinear moderating effects of SCs on the satisfaction-loyalty link. The 
empirical literature has paid very little attention to these functional forms; therefore, we encourage further research in this field.

\section{Conclusions}

The current knowledge is scarce in providing evidence for academics and managers regarding the nonlinear moderating effect of SCs in general and RSCs in particular. Given the importance of these constructs, combined with some inconclusive results from prior research, further insights into their moderating effect on the satisfactionloyalty relationship are paramount. Our study is an important building block of knowledge, as it contributes to our understanding of one of the most important relationships in marketing.

\section{Appendix 1}

Summary statistics.

\begin{tabular}{llll}
\hline & Retailer 1 & Retailer 2 & Retailer 3 \\
\hline Gender (\%) & & & \\
Male & 45 & 49 & 46 \\
Female & 55 & 51 & 54 \\
Age (\%) & & & \\
$<45$ & 43 & 41 & 40 \\
$45-64$ & 48 & 49 & 50 \\
$\geq 65$ & 9 & 10 & 10 \\
Convenient locations & & & 6.93 \\
Average & 7.12 & 7.52 & 2.49 \\
SD & 2.44 & 2.37 & \\
\hline
\end{tabular}

A note on sampling: The survey was administered to members of a representative panel of the US population. Using quota sampling, a total of 15,669 individuals were recruited. Shopping mainly at one of the three retailers was considered eligibility criteria to participate in the study (retailer $1, n=6674$; retailer 2, $n=4254$; retailer $3, n=4741$ ). After deleting incomplete surveys, a total of 15,120 valid questionnaires were obtained (retailer $1, n=6458$; retailer 2, $n=4104$; retailer $3, n=4558$ ). 
Asymmetry.

\begin{tabular}{llll}
\hline & Retailer 1 & Retailer 2 & Retailer 3 \\
\hline Loyalty & & -1.15 & -0.91 \\
Skewness & -0.97 & & \\
Satisfaction & & & -0.68 \\
Skewness & -0.74 & -0.80 & - \\
OSCs & & & \\
Skewness & 0.32 & - & -0.05 \\
RSCs & & -0.12 & \\
Skewness & -0.04 & &
\end{tabular}

\section{Appendix 2}

\section{Scale origins.}

Customer satisfaction (Fornell et al., 1996)

Overall satisfaction (SAT1)

Meet expectations (SAT2)

Overall switching costs (Nagengast et al., 2014; Ping, 1993)

It would take a lot of time and effort to switch to another retailer (OSC1)

In general, it would be a hassle to change retailers (OSC2)

Customer loyalty (Mittal et al., 1998; Vogel et al., 2008)

Six months from now, how likely are you to still be shopping at (retailer)? (CL1)

How likely would you be to recommend (retailer) to friends and colleagues? (CL2)

Relational switching costs (Nagengast et al., 2014)

Brand relationship loss costs

Changing my current retailer will make me uncomfortable since...

I like my retailer's image (BRLC1)

I support the retailer as a firm (BRLC2)

I do not care about the brand/company name of the retailer I use. (r) (BRLC3)

Personal relationship loss costs

Switching to another retailer will be painful for me since...

I have developed a personal friendship with at least one employee at this retailer (PRLC1)

I have a somewhat personal relationship with at least one employee at this retailer (PRLC2)

I am friends with at least one employee at this retailer (PRLC3)

At least one employee is familiar to me personally (PRLC4) 


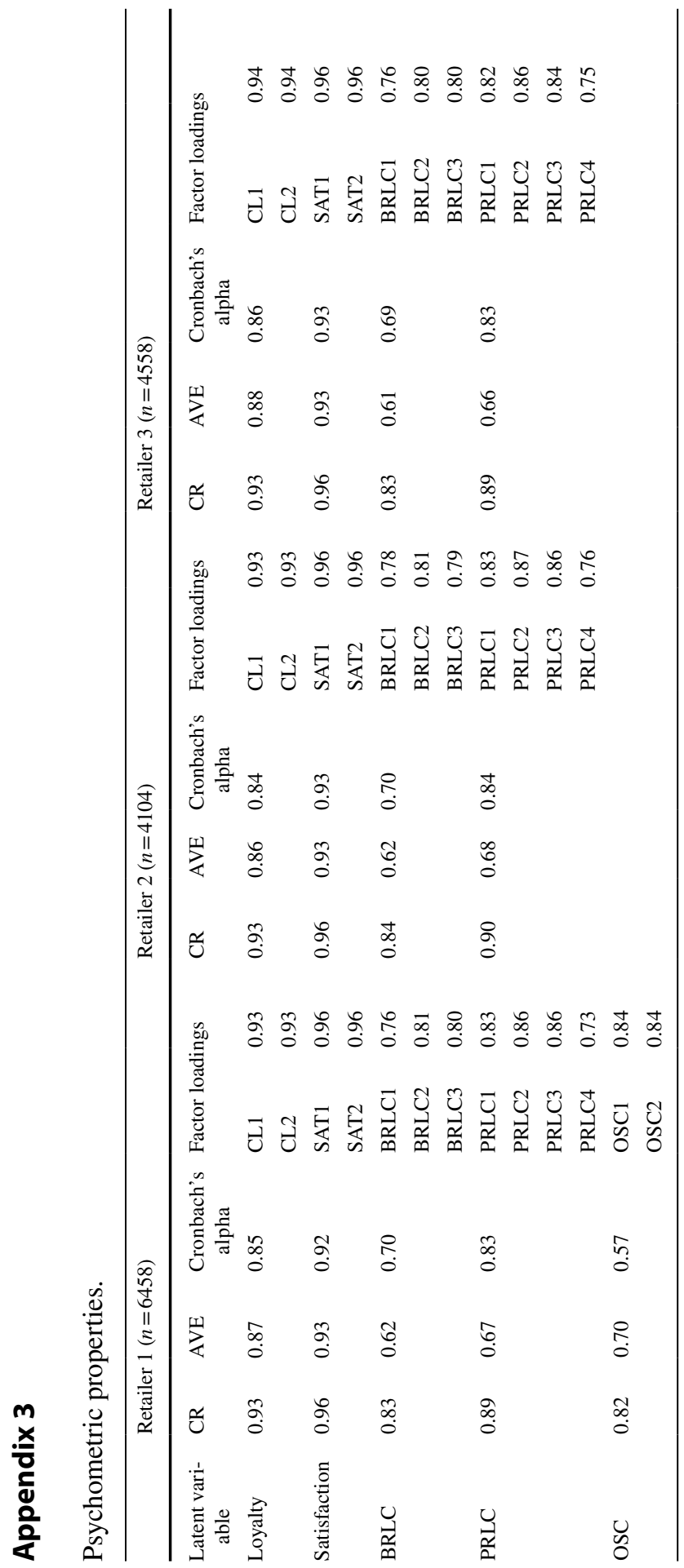


Open Access This article is licensed under a Creative Commons Attribution 4.0 International License, which permits use, sharing, adaptation, distribution and reproduction in any medium or format, as long as you give appropriate credit to the original author(s) and the source, provide a link to the Creative Commons licence, and indicate if changes were made. The images or other third party material in this article are included in the article's Creative Commons licence, unless indicated otherwise in a credit line to the material. If material is not included in the article's Creative Commons licence and your intended use is not permitted by statutory regulation or exceeds the permitted use, you will need to obtain permission directly from the copyright holder. To view a copy of this licence, visit http://creativecommons.org/licen ses/by/4.0/.

\section{References}

Aiken, L. S., \& West, S. G. (1991). Multiple regression: Testing and interpreting interactions. Sage.

Bell, S. J., Auh, S., \& Smalley, K. (2005). Customer relationship dynamics: Service quality and customer loyalty in the context of varying levels of customer expertise and switching costs. Journal of the Academy of Marketing Science, 33(2), 169-183.

Blut, M., Beatty, S. E., Evanschitzky, H., \& Brock, C. (2014). The impact of service characteristics on the switching costs-customer loyalty link. Journal of Retailing, 90(2), 275-290.

Blut, M., Frennea, C. M., Mittal, V., \& Mothersbaugh, D. L. (2015). How procedural, financial and relational switching costs affect customer satisfaction, repurchase intentions, and repurchase behavior: A meta-analysis. International Journal of Research in Marketing, 32(2), 226-229.

Blut, M., Evanschitzky, H., Backhaus, C., Rudd, J., \& Marck, M. (2016). Securing business-to-business relationships: The impact of switching costs. Industrial Marketing Management, 52(1), 82-90.

Burnham, T. A., Frels, J. K., \& Mahajan, V. (2003). Consumer switching costs: A typology, antecedents, and consequences. Journal of the Academy of Marketing Science, 31(2), 109-127.

Chang, H. H., \& Chen, S. W. (2009). Consumer perception of interface quality, security, and loyalty in electronic commerce. Information and Management, 46(7), 411-417.

Darren, G., \& Mallery, P. (2019). IBM SPSS Statistics 25 step by step: A simple guide and reference (Fifteenth). Taylor \& Francis.

Davis-Sramek, B., Droge, C., Mentzer, J. T., \& Myers, M. B. (2009). Creating commitment and loyalty behavior among retailers: What are the roles of service quality and satisfaction? Journal of the Academy of Marketing Science, 37(4), 440-454.

Deville, J.-C. (1991). A theory of quota surveys. Survey Methodology, 17(2), 163-183.

Dick, A. S., \& Basu, K. (1994). Customer loyalty: Toward an integrated conceptual framework. Journal of the Academy of Marketing Science, 22(2), 99-113.

Evanschitzky, H., Ramaseshan, B., Woisetschläger, D. M., Richelsen, V., Blut, M., \& Backhaus, C. (2012). Consequences of customer loyalty to the program and to the company. Journal of the Academy of Marketing Science, 40(5), 625-638.

Evanschitzky, H., Bartikowski, B., Baines, T., Blut, M., Brock, C., Kleinlercher, K., Naik, P., Petit, O., Rudolph, T., Spence, C., Velasco, C., \& Wünderlich, N. V. (2020). Digital disruption in retailing and beyond. Journal of Service Management Research, 4(4), 187-204.

Fornell, C., \& Larcker, D. F. (1981). Evaluating structural equation models with unobservable variables and measurement error. Journal of Marketing Research, 18(1), 39-50.

Fornell, C., Johnson, M. D., Anderson, E. W., Jaesung, C., \& Everitt Bryant, B. (1996). The American customer satisfaction index: Nature, purpose, and findings. Journal of Marketing, 60(4), 7-18.

Haj-Salem, N., \& Chebat, J. C. (2014). The double-edged sword: The positive and negative effects of switching costs on customer exit and revenge. Journal of Business Research, 67(6), 1106-1113.

Harmeling, C. M., Palmatier, R. W., Houston, M. B., Arnold, M. J., \& Samaha, S. A. (2015). Transformational relationship events. Journal of Marketing, 79(5), 39-62.

Jones, M. A., Mothersbaugh, D. L., \& Beatty, S. E. (2000). Switching barriers and repurchase intentions in services. Journal of Retailing, 76(2), 259-274.

Jones, M. A., Mothersbaugh, D. L., \& Beatty, S. E. (2002). Why customers stay: Measuring the underlying dimensions of services switching costs and managing their differential strategic outcomes. Journal of Business Research, 55(6), 441-450. 
Jones, M. A., Reynolds, K. E., Mothersbaugh, D. L., \& Beatty, S. E. (2007). The positive and negative effects of switching costs on relational outcomes. Journal of Service Research, 9(4), 335-355.

Lee, J., Lee, J., \& Feick, L. (2001). The impact of switching costs on the customer satisfaction-loyalty link: Mobile phone service in France. Journal of Services Marketing, 15(1), 35-48.

Love, E., Staton, M., \& Rotman, J. D. (2016). Loyalty as a matter of principle: The influence of standards of judgment on customer loyalty. Marketing Letters, 27, 661-674.

Mende, M., Thompson, S. A., \& Coenen, C. (2015). It's all relative: How customer-perceived competitive advantage influences referral intentions. Marketing Letters, 26, 661-678.

Mittal, V., Ross, W. T., Jr., \& Baldasare, P. M. (1998). The asymmetric impact of negative and positive attribute-level performance on overall satisfaction and repurchase intentions. Journal of Marketing, 62(1), 33-47.

Muthen, B., \& Kaplan, D. (1985). A comparison of some methodologies for the factor analysis of nonnormal Likert variables. British Journal of Mathematical and Statistical Psychology, 38, 171-189.

Nagengast, L., Evanschitzky, H., Blut, M., \& Rudolph, T. (2014). New insights in the moderating effect of switching costs on the satisfaction-repurchase behavior link. Journal of Retailing, 90(3), 408-427.

Patterson, P. G., \& Smith, T. (2003). A cross-cultural study of switching barriers and propensity to stay with service providers. Journal of Retailing, 79(2), 107-120.

Pick, D., \& Eisend, M. (2014). Buyers' perceived switching costs and switching: A meta-analytic assessment of their antecedents. Journal of the Academy of Marketing Science, 42(2), 186-204.

Ping, R. A. (1993). The effects of satisfaction and structural constraints on retailer exiting, voice, loyalty, opportunism, and neglect. Journal of Retailing, 69(3), 320-352.

Popkowski Leszczyc, P. T. L., \& Timmermans, H. J. P. (1997). Store-switching behaviour. Marketing Letters, 8(2), 193-204.

Price, L. L., \& Arnould, E. J. (1999). Commercial friendships: Service provider-client relationships in context. Journal of Marketing, 63(October), 38-56.

Rusbult, C. E. (1980). Satisfaction and commitment in friendships. Representative Research in Social Psychology, 11(2), 96-105.

Sashi, C. M. (2012). Customer engagement, buyer-seller relationships, and social media. Management Decision, 50(2), 253-272.

Swaminathan, V., Page, K. L., \& Gürhan-Canlie, Z. (2007). 'My' brand or 'Your' brand: The effects of brand relationship dimensions and self-construal on brand evaluations. Journal of Consumer Research, 34(2), 248-259.

Vogel, V., Evanschitzky, H., \& Ramaseshan, B. (2008). Customer equity drivers and future sales. Journal of Marketing, 72(6), 98-108.

Yang, Z., \& Peterson, R. T. (2004). Customer perceived value, satisfaction, and loyalty: The role of switching costs. Psychology \& Marketing, 21(10), 799-822.

Publisher's Note Springer Nature remains neutral with regard to jurisdictional claims in published maps and institutional affiliations. 